\title{
Assessing the impact of photovoltaic self-consumption support policies on energy losses
}

\author{
J. García-Villalobos, P. Eguía, E. Torres, A. Etxegarai \\ Department of Electrical Engineering - University of Basque Country - UPV/EHU \\ Alda. Urquijo, s/n, 48013 Bilbao (Spain) \\ e-mail: javier.garciav@ehu.eus
}

\begin{abstract}
In recent years, self-consumption concept has been gaining more and more importance within the energy model of developed countries. Specifically, the number of photovoltaic (PV) self-consumption installations has grown strongly due to cost reductions. In this context, different regulatory frameworks are being developed in order to regulate the deployment of this type of installations. The regulatory framework will also have an important impact on energy losses. In this paper, an analysis on how energy losses are affected by two different regulatory framework approaches ("instantaneous or realtime self-consumption scheme" and "net-metering scheme") is presented. A significant region of Spain (Murcia) and real data of load demand have been used. Simulation results show a decrease of energy losses at low self-consumption adoption levels with both regulatory frameworks. However, energy losses increase at medium and high adoption levels when net-metering scheme is used.
\end{abstract}

\section{Keywords}

Self-consumption, PV, net-metering, energy losses, regulatory framework

\section{Introduction}

Currently, there is an important discussion about selfconsumption concept and how it should be deployed in order to reduce greenhouse gas emissions while the power system is affected as less as possible. As a consequence, developed countries have established a series of different regulations about self-consumption [1]. Mostly, selfconsumption is accepted by all countries but there are significant differences about the financial compensation to self-consumption installation owners (prosumers) for the excess energy injected back into the grid. In this sense, prosumers get:

- No payment at all in Spain.

- A payment linked to the wholesale electricity market prices in China, Germany, Italy, Sweden, Switzerland, etc.

- A feed-in tariff, between the wholesale and retail electricity market prices, in Denmark.
- The retail prices in some parts of Belgium, Brazil, some regions of Canada, Israel, Mexico, the Netherlands and several states of USA. This scheme is known as pure net-metering.

- A higher value than the retail prices in UK. These different ways of compensation, together with the PV system size, will define the payback period of the PV self-consumption installation. That is, in some countries, it is profitable for prosumers to inject the excess energy to the grid as it will allow a faster payback time. However, in other countries PV self-consumption installations should be dimensioned to reduce as much as possible the excess energy (very high self-consumption rate) as it will only increase investment costs. A study carried out in [2] claims that a $40 \%$ of self-consumption rate is profitable in southern regions of Europe such as Spain. Additionally, this research work also points out that Spanish prosumers must dimension their installations to self-consume as much produced energy as possible. At the other extreme, in countries where net-metering is allowed, PV self-consumption installations may be dimensioned to cover $100 \%$ of energy needs of prosumers.

PV self-consumption installations have an influence on the value of energy losses in the network. There are several studies that analyze this relationship. Mendez et al. evaluate in [3] the effect of distributed generation on energy losses for different penetration levels using the IEEE34 node test feeder, obtaining that energy losses present a U-shaped characteristic as distributed generation penetration level increases. That is, energy losses start to decrease at low penetration levels, then a minimum is reached (turning point) and afterwards, energy losses begin to increase until $100 \%$ of penetration level is achieved. In addition, energy losses at high penetration levels could be higher than in the base case scenario (without DG). In the case of PV selfconsumption this U-shaped curve will depend largely on the overlap of the locally consumed and produced energy. In other words, it depends on the real-time selfconsumption rate, strongly influenced by the regulatory framework.

In [4] the impact of PV deployment in terms of costs and distribution energy losses is analyzed considering a 
reference network adapted to different characteristics of locations and PV penetration levels. Six different locations in USA and two different type of areas (low and high population density) are used in the analysis. Regarding energy losses, the study shows a decrease of energy losses for low PV self-consumption penetration levels and an increase for penetration levels above $25 \%$. According to [5] the turning point may be around $10 \%$ of PV selfconsumption penetration rate, but it varies depending on the country or region.

In [6] an actual distribution grid in northern Germany with a high share of PV and wind energy is considered to determine the distribution of energy losses through the different voltage levels. In the case of LV losses, load flow cannot be readily applied and several grid classes with different average network impedance were considered.

Other related work is focused on searching the optimal allocation of distributed generation to minimize energy losses in distribution networks [7], analyzing the impact on reactive power flow of $\mathrm{PV}$ inverters with a power factor of one [8] and developing a reactive power control for PV inverters [9]-[11].

In this context, the current paper analyzes the energy losses (fixed and variable technical losses) produced by PV self-consumption in the region of Murcia (Spain) for two different regulatory frameworks: instantaneous selfconsumption (ISC) and net-metering (NM). These regulatory frameworks will have an impact in the design conditions and dimensions of future PV self-consumption installations. Therefore, the impact on energy losses of each regulatory framework will be different.

The paper is organized as follows. Section 2 introduces the methodology applied in the analysis while section 3 presents the electric network used in this research work. Section 4 shows the results from the simulation of the different self-consumption scenarios. Finally, section 4 presents the main conclusions of the paper and proposes possible future research works.

\section{Methodology}

The proposed methodology relies on the creation of various scenarios with different PV self-consumption adoption levels.

\subsection{Modelling PV self-consumption installations}

In order to model PV self-consumption installations, a regulatory framework should be defined. Two different self-consumption policies have been considered: instantaneous self-consumption scheme and net-metering scheme. In the case of ISC, prosumers do not have any economic return when the excess of PV energy is injected in the network. Therefore, PV self-consumption installation must be dimensioned to minimize payback time. Thus, PV self-consumption installation is designed to provide $40 \%$ of the annual energy demand of the prosumer [2]. Conversely, in a NM scenario, prosumers dimension their PV installation in order to cover $100 \%$ of their energy needs.

Self-consumption installations have been placed randomly along the whole network until a specified PV self-consumption adoption level is achieved. The PV self-consumption adoption level is the number of customers with PV self-consumption installation versus the total number of customers. Eleven different levels, from $0 \%$ to $100 \%$ in steps of $10 \%$, have been considered for both regulatory frameworks.

Both LV and MV customers are candidates to house a PV self-consumption installation. When a specific customer is selected to allocate a PV self-consumption installation, the PV system size is calculated, taking into account the annual energy demand of the customer, and an equivalent generator is placed in the network node of the customer.

As a consequence, total PV self-consumption installed power depends on the regulatory framework applied, as shown in Table 1. Note that PV installed power for $100 \%$ adoption level of the ISC case approximately coincides with $40 \%$ adoption level of the NM case.

Finally, Photovoltaic Geographical Information System (PVGIS) database [12] has been used to determine hourly generation of each PV self-consumption installation.

\subsection{Study procedure}

The analysis has been carried out by means of PSS®E. Several scripts have been developed using Python language to create and manage the different scenarios and to calculate energy losses for each simulation case. The grid is segmented in three levels, HV; MV and LV and the following procedure is applied:

- First step, MV energy losses are calculated using the flowchart shown in Figure 1. The number of PV self-consumption installations are increased sequentially until $100 \%$ penetration level is achieved. When a PV self-consumption scenario is defined, an hourly load flow is executed and energy losses are calculated for the MV distribution network. Additionally, active and reactive power at each HV/MV supply point and MV/LV demand point are saved.

- Second step, LV energy losses are calculated using power flow data saved in step one. The power demand at each MV/LV connection point is uniformly distributed among all nodes of the corresponding LV distribution network. With this assumption, energy losses at LV level are underestimated, and rather conservative, because of the uniform distribution of loads and PV generation.

- Third step, HV energy losses are calculated, using power flows at HV/MV connection points saved in step one. The generation connected to the HV transmission network is scaled in order to accommodate the new PV generation included in the MV and LV networks.

Table 1. Installed PV power in MW depending on the adoption level and regulatory framework

\begin{tabular}{|c|c|c|c|c|c|c|c|c|c|c|c|}
\hline & \multicolumn{10}{|c|}{ PV self-consumption adoption level } \\
\hline & & $10 \%$ & $20 \%$ & $30 \%$ & $40 \%$ & $50 \%$ & $60 \%$ & $70 \%$ & $80 \%$ & $90 \%$ & $100 \%$ \\
\hline 3 & ISC & 117 & 235 & 353 & 470 & 589 & 707 & 825 & 943 & 1,060 & 1,177 \\
\hline 8 & NM & 296 & 591 & 886 & 1,181 & 1,478 & 1,776 & 2,071 & 2,366 & 2,661 & 2,952 \\
\hline
\end{tabular}




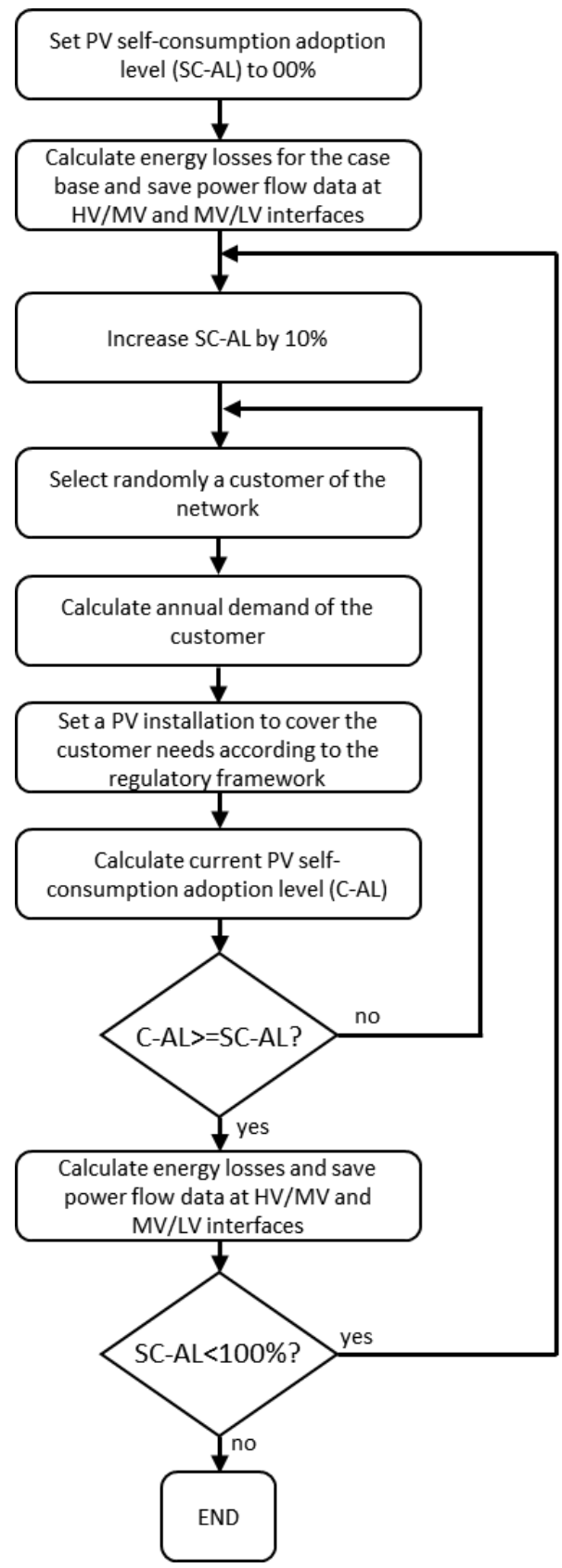

Figure 1. Procedure for calculation of electric losses in the MV network

Energy losses are calculated for a year using detailed hourly calculations for eight representative days: one working day and one holiday for each season. From these results the annual energy losses have been estimated using (1).

$$
L_{y e a r}=\left(26 \cdot \sum_{x=1}^{4} L_{x}^{h d}+65 \cdot \sum_{y=1}^{4} L_{y}^{w d}\right) \cdot \frac{365}{364}
$$

where $L_{x}^{h o}$ is the energy losses for the holiday $x$ and $L_{y}^{w d}$ is the energy losses for the working day $y$, being $x$ and $y$ the list of analyzed holidays and working days, respectively.

\section{Network and data description}

Using the methodology described in Section 2, the influence of PV self-consumption installed in the region of Murcia, on the energy losses for the year 2014 has been determined [13]. The study includes the LV and MV distribution networks of Murcia and the entire HV Spanish transmission network, as shown in Figure 2.

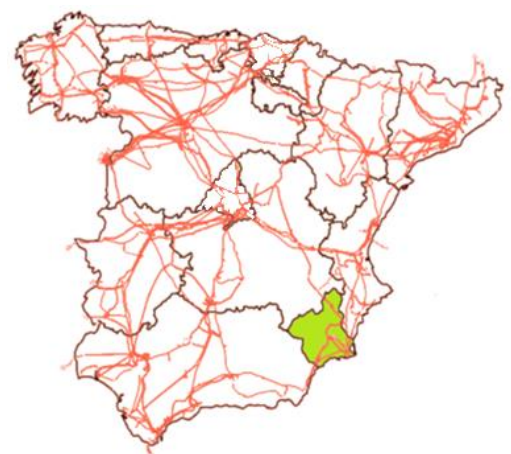

Figure 2. Map of the HV electric transport system in Spain. In green, the region of Murcia.

The three different voltage levels (HV, MV and LV) have been analyzed separately due to limits in the number of nodes of the simulation software.

- The HV network (voltage $>20 \mathrm{kV}$ ) covers the whole Spanish transmission and sub-transmission networks and their interconnections with Portugal, France and Morocco. The aim for including this network is to analyze the influence of a large-scale deployment of PV self-consumption systems.

- The MV network comprises the whole distribution network (from $1 \mathrm{kV}$ to $20 \mathrm{kV}$ ) of the region of Murcia (Figure 3), composed of 90 radial feeders (parts of the MV network fed by a single HV connection point) and more than $30 \mathrm{k}$ lines. This network has a meshed layout but it is radially operated. The total net energy demand for the study year 2014 is $6.09 \mathrm{TWh}$.

- The LV network (voltage $<1 \mathrm{kV}$ ) is composed by a selected set of forty LV distribution networks (about $5 \%$ of total) which are fed from the MV distribution network. Total energy losses are obtained scaling the results of the analyzed portion of the LV network. This simplification is carried out because not all LV network models are available. The total energy demand of the LV distribution network is $3.12 \mathrm{TWh}$ for the study year.

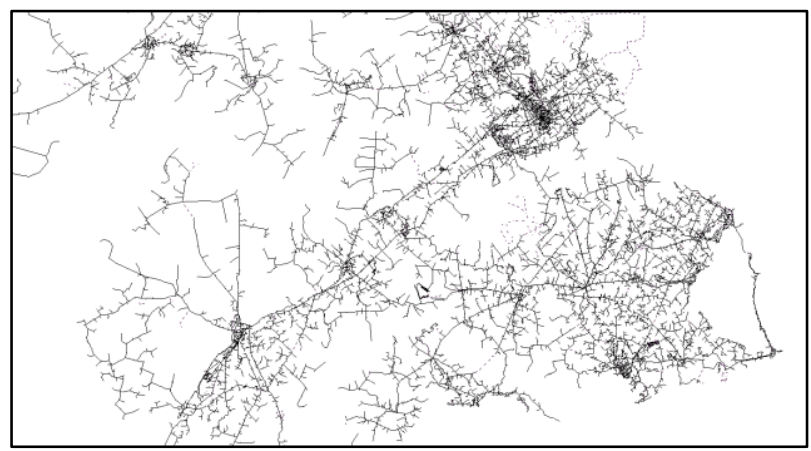

Figure 3. MV distribution network of Murcia

Table 2 shows the number of the different elements included in each network. The number of generators depends on the number of PV self-consumption installations of the simulation scenario. 
Table 2. General data of simulated networks

\begin{tabular}{|c|c|c|c|c|c|c|}
\cline { 2 - 7 } \multicolumn{1}{c|}{} & Areas & Nodes & Generators & Loads & Transf. & Lines \\
\hline HV network & 1 & 2674 & 655 & 989 & 1243 & 3788 \\
\hline MV network & 90 & 31721 & up to 15388 & 15388 & 94 & 33327 \\
\hline LV network & 40 & 19020 & up to 13651 & 13651 & 71 & 18949 \\
\hline
\end{tabular}

Real consumption data at MV distribution network in 2014 has been used for eight representative days $\left(22^{\text {nd }}\right.$ and $25^{\text {th }}$ February, $5^{\text {th }}$ and $11^{\text {th }}$ May, $1^{\text {st }}$ July, $27^{\text {th }}$ September and $15^{\text {th }}$ and $25^{\text {th }}$ October). Load curve of each day is shown in Figure 4.

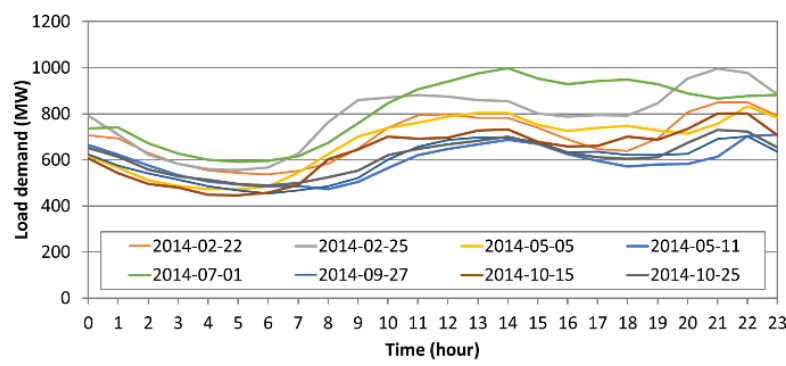

Figure 4. Load demand of the region of Murcia for the analyzed eight days

\section{Study results}

In this section, the results obtained in the analysis for both regulatory frameworks are described and compared with the losses corresponding to the base case. Table 3 shows losses for the base case without PV generation. Two important aspects about these results should be mentioned. On the one hand, the loss coefficient for LV and MV networks is $4.1 \%$ which is in the low range of expected values. For example, the value for Spain in 2008 was $7.1 \%$ [14]. However, it should be taken into account that the calculated energy losses do not include non-technical losses and technical losses due to effects such as no linearity of loads, phase unbalances, load demand variations of less than an hour, etc. On the other hand, the gross demand (load demand plus losses) calculated with the model presents an error of $2.34 \%$ with respect to the real data acquired from the DSO that operates in Murcia.

Table 3. Overall results of the base case

\begin{tabular}{|l|c|c|c|}
\hline & $\begin{array}{c}\text { Demand } \\
(\text { GWh) }\end{array}$ & $\begin{array}{c}\text { Losses } \\
(\text { GWh) }\end{array}$ & $\begin{array}{c}\text { Loss } \\
\text { Coef. (\%) }\end{array}$ \\
\hline LV network & 3121.36 & 124.43 & $4.15 \%$ \\
\hline MV network & 2977.35 & 120.63 & $1.98 \%$ \\
\hline LV+MV & 6098.71 & 245.06 & $4.10 \%$ \\
\hline Gross demand & 6219.34 & - & - \\
\hline
\end{tabular}

In the following subsections study results are presented, in function of the regulatory scheme used. In the first one, instantaneous or real-time self-consumption results are shown while in the second one, net-metering results are shown. Finally, a comparison between both regulatory frameworks in terms of energy losses is presented.

\subsection{Case A. Instantaneous self-consumption scheme}

When a PV self-consumption installation is designed under an instantaneous self-consumption scheme, PV installed power is minimized as well as the exports to the network, that is, the installation maximizes the selfconsumption rate. This is clearly shown in Figure 5 and
Figure 6, where hourly load and PV generation are shown for a self-consumption adoption level from 10 to $100 \%$, for a winter and a summer day, respectively.

In a typical winter day, PV peak power could nearly cover total energy demand at $13 \mathrm{~h}(\mathrm{GMT}+1)$. On the other hand, in July, PV peak power is at $14 \mathrm{~h}(\mathrm{GMT}+2)$, coinciding with the maximum load demand. In this case, there is a small injection of energy from MV to $\mathrm{HV}$ network for the case of $100 \%$ of PV self-consumption adoption level.

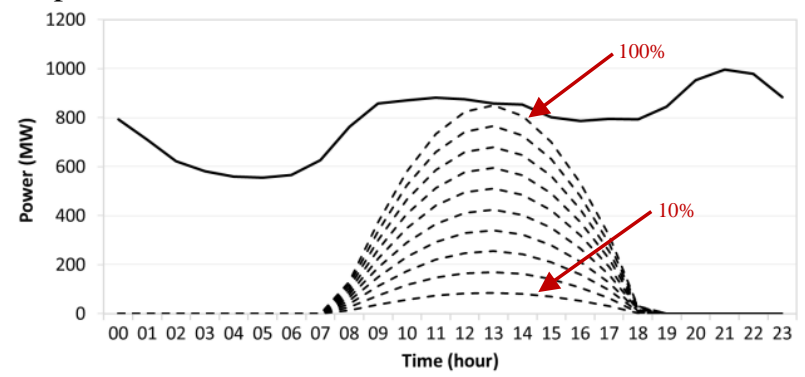

Figure 5. Load demand (February) versus PV generation for 10 to $100 \%$ adoption levels (ISC case)

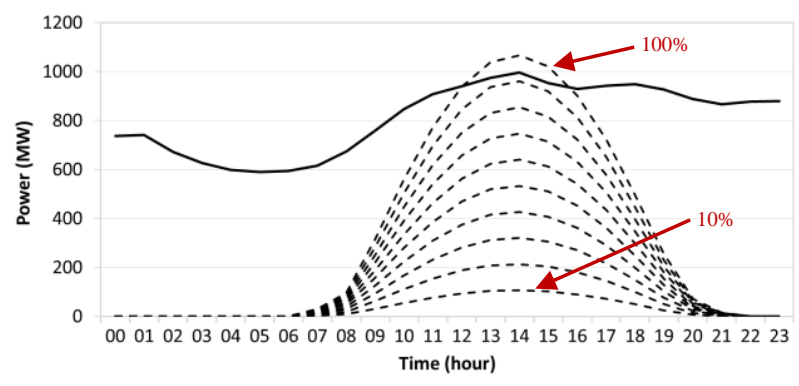

Figure 6. Load demand (July) versus PV generation for 10 to $100 \%$ adoption levels (ISC case)

Figure 7 shows the annual variation of energy losses in the network for each voltage level. As it can be seen in the figure, energy losses are reduced in all voltage levels. LV and MV network are noticeably more influenced by the introduction of PV self-consumption. In contrast, HV network is almost not affected. With an instantaneous self-consumption scheme, there is no turning point in energy losses and therefore, losses are reduced for all PV self-consumption adoption levels. The maximum reduction is achieved for $100 \%$ adoption level with $33.76 \%, 31.47 \%$ and $0.97 \%$ for $\mathrm{LV}, \mathrm{MV}$ and $\mathrm{HV}$ networks, respectively.

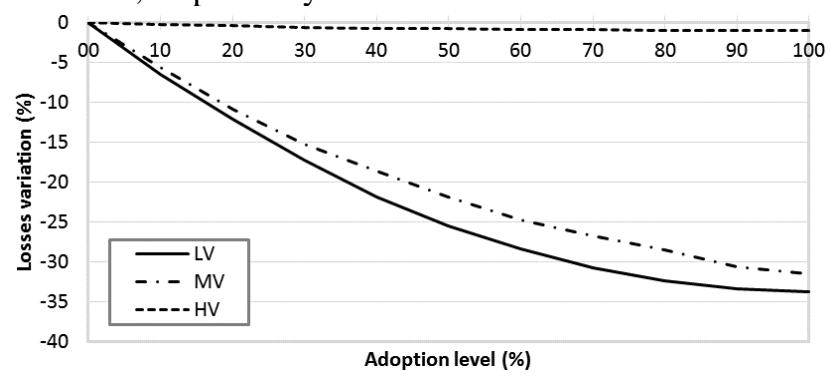

Figure 7. Variation of energy losses for the ISC case as a function of adoption level for 0 to $100 \%$

\subsection{Case B. Net-metering scheme}

When PV self-consumption installations are designed under a net-metering scheme, the maximum PV power generation could exceed substantially the load demand, 
especially during the central hours of the day. This is clearly shown in Figure 8 and Figure 9, where hourly load and PV generation are depicted for a typical winter and summer day, respectively. Either in winter or summer, PV peak power could be more than two times the total energy demand at midday if all customers adopt self-consumption. Thus, there could be an important injection of energy from LV and MV networks to HV network, at high PV selfconsumption adoption levels.

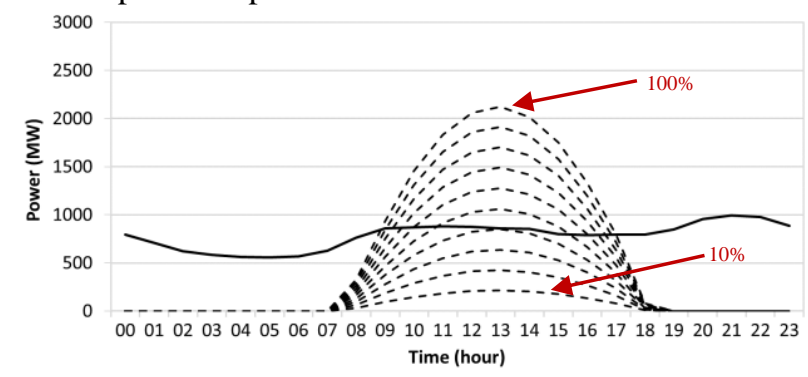

Figure 8. Load demand (February) versus PV generation for 10 to $100 \%$ adoption levels (NM case)

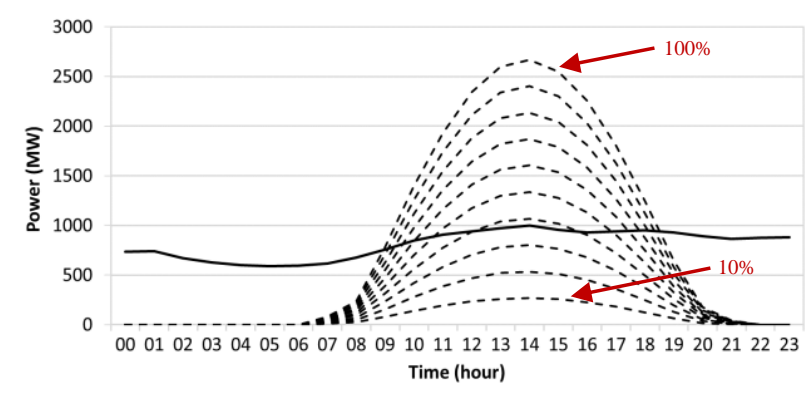

Figure 9. Load demand (July) versus PV generation for 10 to $100 \%$ adoption levels (NM case)

Figure 10 shows the annual variation of energy losses for each voltage level. As it can be seen in this figure, energy losses describe a U-shaped curve, especially in LV and MV networks. As in the previous case, the HV network is less affected. With a net-metering scheme, there is a turning point in energy losses located at around $40 \%$ of PV self-consumption adoption level. The maximum energy losses reduction achieved at this adoption level is $30.08 \%$, $24.3 \%$ and $0.99 \%$ for LV, MV and HV network, respectively. Beyond this point, energy losses start to increase, being higher than energy losses in the base case when PV adoption level achieves a value higher than $80 \%$. For $100 \%$ adoption level, energy losses increase by $22.73 \%, 22.07 \%$ and $1.07 \%$ for LV, MV and HV network, respectively.

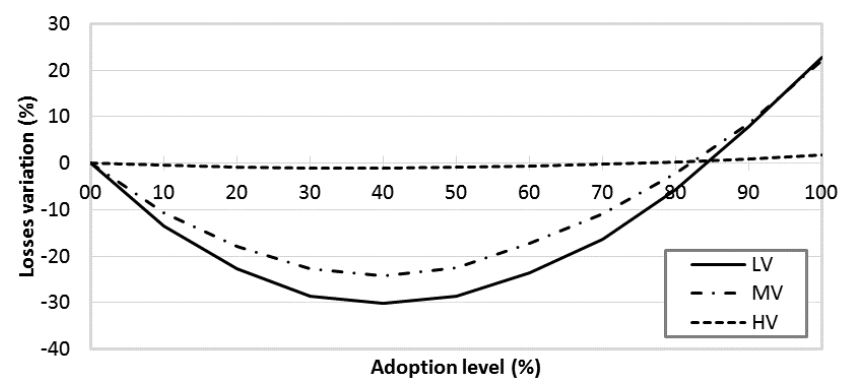

Figure 10. Variation of energy losses for the NM case as a function of adoption level for 0 to $100 \%$

For large adoption levels, energy losses could be reduced using different strategies which are mainly based on shifting or creating new energy demand at the times when there is a high PV production. Demand side management and energy storage can play an important role to reduce this issue [15]. Additionally, grid reinforcements will be necessary most of the times, even for moderate adoption levels, as shown in the next subsection.

\subsection{Comparison of regulatory approaches}

It is interesting to make a comparison of both regulatory frameworks using the same PV self-consumption penetration level, that is, with the same amount of installed PV power. Under these conditions, ISC is more efficient than NM, as can be seen in Figure 11, because losses reduce more for the same penetration level. For a PV self-consumption penetration rate of $40 \%$, losses are $13 \%$ lower in the LV distribution network with ISC regulation than with NM. Similarly, losses in the MV network are $29 \%$ lower with ISC regulation than with NM.

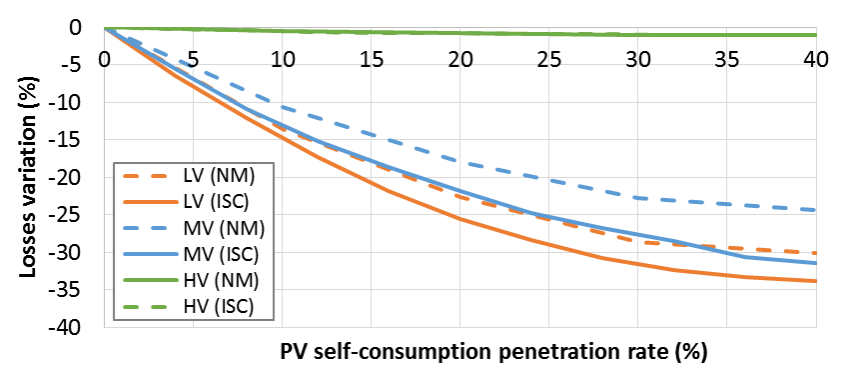

Figure 11. Variation of losses for the different regulatory frameworks per voltage level

Besides the impact on energy losses, PV installations impact the voltage in the network. Active power injected by PV inverters increases the voltage at the connection point and the surrounding network buses. This impact depends also on the regulatory framework, and appears at moderate PV self-consumption penetration rates. Figure 12 shows the percentage of MV network nodes with a voltage equal to or greater than $1.05 \mathrm{pu}$, for both regulatory regimes and for $40 \%$ self-consumption penetration rate (same PV installed power). The number of network nodes with high voltage values is lower with ISC regulatory framework than with NM.

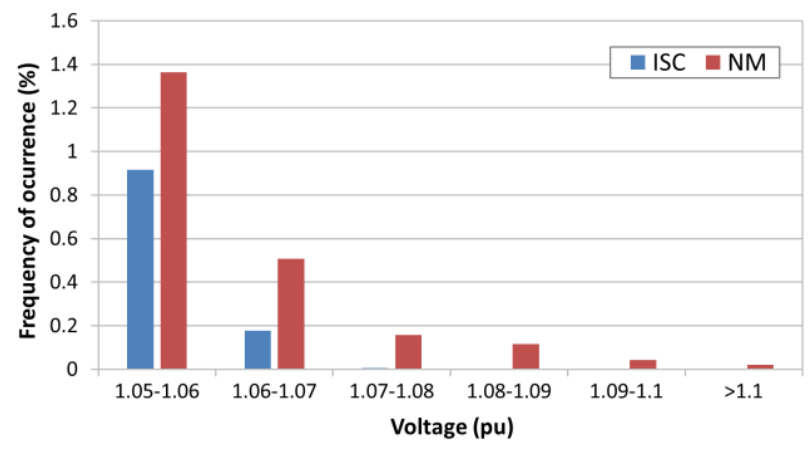

Figure 12. Node voltage distribution of the MV network for a $40 \%$ of PV self-consumption penetration rate 


\section{Conclusions and future work}

The selection of the self-consumption regulatory framework has an important impact on energy losses, as the later are influenced by the installed power of the PV self-consumption installations which, in turn, depends on the economic value assigned by the regulatory framework to the energy produced. In this sense, this paper analyzes two different policies, instantaneous self-consumption and net-metering.

Twenty different PV self-consumption scenarios have been analyzed in order to quantify the variation of energy losses due to the presence of a significant number of PV selfconsumption, using the region of Murcia (Spain) as an application case. In terms of energy losses, simulation results show that ISC regulatory framework is more efficient, not only at the same adoption level but also at the same quantity of installed power. Furthermore, the netmetering regulatory framework has a greater impact on voltage levels, which can exceed the allowed values for the LV and MV distribution networks.

In order to minimize these impacts, it is desirable to avoid or minimize energy exports from PV self-consumption installations. This will limit the possible electricity rate increases caused by the grid reinforcement needs. In these sense, demand side management or distributed energy storage could allow a better integration of such type of installations.

It should be pointed out that these results have been obtained using a favorable hypothesis in terms of PV selfconsumption geographic distribution. Nevertheless, it is expected that this type of installations will be more concentrated in rural areas because of roof and floor space availability, income level and other reasons.

Therefore, future work may include the influence of geographic dispersion or concentration of PV selfconsumption installations on energy losses, the impact of PV self-consumption in voltage levels and possible solutions to improve their technical integration in electric distribution networks.

\section{Acknowledgements}

This research was supported by the "Energía y Sociedad" dissemination platform and the Basque Government (Ref. IT 1083-16). Additionally, authors would like to thank Iberdrola Company for all data provided for the application case.

\section{References}

[1] G. Masson, J. I. Briano, and M. J. Baez, "Review and Analysis of Self-consumption Policies," 2016. [Online]. Available: http://www.sunwindenergy.com/sites/default/files/iea-pvps__self-consumption_policies_-_2016_-_2_0.pdf.

[2] L. De Boeck, S. Van Asch, P. De Bruecker, and A. Audenaert, "Comparison of support policies for residential photovoltaic systems in the major EU markets through investment profitability," Renew. Energy, vol. 87, pp. 42-53, 2016

[3] V. H. Méndez Quezada, J. Rivier Abbad, and T. Gómez San Román, "Assessment of energy distribution losses for increasing penetration of distributed generation," IEEE Trans. Power Syst., vol. 21, no. 2, pp. 533-540, 2006.

[4] MIT, The Future of Solar Energy - An interdisciplinary MIT study, no. 3. 2015.

[5] D. Pudjianto, P. Djapic, J. Dragovic, and G. Strbac, "Grid Integration Cost of PhotoVoltaic Power Generation Direct Costs Analysis related to Grid Impacts of Photovoltaics," 2013.

[6] T. Reimann, J. Dasenbrock, A. Scheidler, M. Braun, W. Heckmann, H. Barth, M. A. Chenjie, and L. Hamann, "Detailed analysis of network losses in a million customer distribution grid with high penetration of distributed generation," 22nd Int. Conf. Exhib. Electr. Distrib. (CIRED 2013), no. 1478, pp. 1478-1478, 2013.

[7] L. F. Ochoa and G. P. Harrison, "Minimizing energy losses: Optimal accommodation and smart operation of renewable distributed generation," IEEE Trans. Power Syst., vol. 26, no. 1, pp. 198-205, 2011.

[8] A. Spring, G. Wirth, G. Becker, R. Pardatscher, and R. Witzmann, "Grid Influences from Reactive Power Flow of Photovoltaic Inverters with a Power Factor Specification of One," IEEE Trans. Smart Grid, vol. 7, no. 3, pp. 1222-1229, May 2016.

[9] E. Dall'Anese, S. V. Dhople, B. B. Johnson, and G. B. Giannakis, "Decentralized optimal dispatch of photovoltaic inverters in residential distribution systems," IEEE Trans. Energy Convers., vol. 29, no. 4, pp. 957-967, 2014

[10] A. Cagnano, E. De Tuglie, M. Liserre, and R. A. Mastromauro, "Online optimal reactive power control strategy of PV inverters," IEEE Trans. Ind. Electron., vol. 58, no. 10, pp. 4549-4558, 2011

[11] K. Turitsyn, P. Šulc, S. Backhaus, and M. Chertkov, "Options for control of reactive power by distributed photovoltaic generators," Proc. IEEE, vol. 99, no. 6, pp. 1063-1073, 2011.

[12] "PVGIS database." [Online]. Available: http://re.jrc.ec.europa.eu/pvgis/.

[13] P. Eguia, E. Torres, and J. García-Villalobos, "GEDISPER Distributed generation impacts on network losses," 2016. [Online]. Available: http://www.energiaysociedad.es/wpcontent/uploads/2016/11/Final-Report-GEDISPER-EN-versionv0.compressed.pdf.

[14] Ergeg, "Treatment of Losses by Network Operators ERGEG Position Paper for public consultation," 2008.

[15] Tractebel Engineering and Ecofys, "Identifying Energy Efficiency improvements and savings potential in energy networks, including analysis of the value of demand response," 2015 